\title{
THE IMPEDANCE CHARACTERIZATION OF HYBRID CNT-SILICA EPOXY NANOCOMPOSITES
}

\author{
R.N. Othman ${ }^{1,2, *}$ and A.N. Wilkinson ${ }^{1}$ \\ ${ }^{1}$ Materials Science Centre, School of Materials, University of Manchester, Grosvenor \\ Street, Manchester, M13 9PL, United Kingdom. \\ ${ }^{2}$ Department of Mechanical Engineering, National Defence University Malaysia, Kem \\ Sungai Besi, 57000 Kuala Lumpur, Malaysia \\ *Email: izawati@upnm.edu.my \\ Phone: +60390513400; Fax: +60390513472
}

\begin{abstract}
Carbon nanotubes grafted onto the surfaces of spherical silica gels were incorporated into epoxy polymer to yield nanocomposite. The efficiency of this approach in controlling the dispersion of carbon nanotubes within the epoxy matrices was observed from the scanning electron microscope images, where the nanotubes remained strongly attached to the surface of the gel. As the micron-sized silica introduced a large excluded volume within the polymer matrices, the nanotubes dispersion remained restricted to a region along the silica surface and bundle formation was prevented. This arrangement aided the formation of an electrically conductive network in an epoxy matrix, where the critical percolation threshold $\left(p_{\mathrm{c}}\right)$ was calculated as $p_{\mathrm{c}}=0.5 \mathrm{wt}$., which is equivalent to 0.16 wt. $\%$ nanotubes, as previously determined from thermal gravimetric analysis. The equivalent circuit model to represent the electrical properties was proposed to analyse the interactions between the real impedance ( $\left.Z^{\prime}\right)$ and imaginary impedance ( $Z^{\prime \prime}$ ) components of the hybrid nanocomposites. The two parallel RC circuits were found to fit the data well, describing the interaction between epoxy and conductive silicananotubes hybrid.
\end{abstract}

Keywords: Hybrid carbon nanotubes; epoxy; equivalent circuit model; impedance properties.

\section{INTRODUCTION}

Carbon nanotubes (CNTs) have proven to be a multifunctional reinforcement that enhances the mechanical [1-4] and electrical [5] properties of composites. Large-scale production causes the CNTs to be easily entangled, making it difficult to disperse them in polymer matrix [6]. As such, chemical functionalization, in situ polymerization, and enhanced polymer blending have been performed to address this dispersion issue [6]. Growing CNTs directly onto fibres [7-9] or microparticle [10-12] substrates provides an alternative to tackle the issues associated with dispersion within polymer matrices. In this way, these substrates not only provide sites for CNT growth, but also function as a carrier to disperse CNTs into polymer matrices. Direct growth of CNTs on particulate substrates has been demonstrated on silica [10, 11, 13] and stainless steel [14]. Moreover, the CNTs grown on alumina particles $\left(\mu \mathrm{Al}_{2} \mathrm{O}_{3}\right)$ result in an increase in thermal conductivity in an epoxy matrix [12]. The growth of CNTs on silica microparticles was performed via the floating catalyst chemical vapour deposition 
method and reported elsewhere [15-17]. A large excluded volume is introduced within the matrices since the silica gel used is in micron size. As such, the CNTs growth remains restricted to regions along the silica surface, which shows that this hybrid structure is conductive. The impedance behaviour in their composite form is further reported in this paper.

\section{EXPERIMENTAL DETAILS}

CNTs were grafted on the surface of spherical silica gel via the floating catalyst chemical vapour deposition method. The hybrid particles, referred to as SG6_3 in this work (Figure 1), were synthesized under optimized conditions of 3 hours reaction time and $760{ }^{\circ} \mathrm{C}$ reaction temperature, using a toluene and ferrocene mixture; the detailed procedure was described in Othman et al. [15]. Araldite ${ }^{\circledR}$ LY556 (Huntsman)epoxy resin was used as a polymer to study the electrical properties of SG6_3, with room temperature viscosity of 10,000-12,000 mPa.s. Various loadings of SG6_3 $(0.5,1,2$, and $5 \mathrm{wt} . \%$ ) were added to the degassed epoxy. Thermal gravimetric analysis(TGA) confirmed that the yield of CNTs grown under these optimum conditions was $33.6 \pm$ 0.37 wt.\% [15]. As such, the corresponding carbon addition was $0.17,0.34,0.66$, and 1.68 wt.\%, respectively.

For the preparation of composites, hardener was added to the mixtures at a constant mix ratio (by wt.\%) of 100: 23 (Araldite ${ }^{\circledR}$ LY 556: XB 3473), as recommended by the manufacturer. The mixture was stirred for another hour at $200 \mathrm{rpm}$ before being cured at $140{ }^{\circ} \mathrm{C}$ for 8 hours. For conductivity measurement, the composites were cut into rectangular squares before applying silver paint to both ends of the film. An Impedance Analysis Interface/NumetriQ PSM 1735 was used to record the samples' conductivity at a frequency range of $1-10^{6} \mathrm{~Hz}$ and voltage amplitude of $1.0 \mathrm{~Hz}$. As a comparison, non-grafted CNT (produced by Nanocyl) was also incorporated into the epoxy resin at the same carbon loading to yield the respective composites.

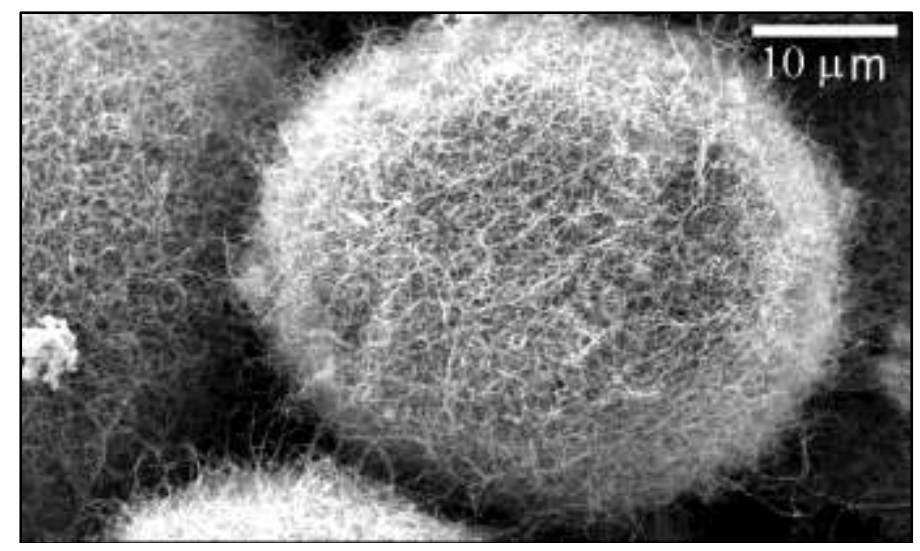

Figure 1. Low magnification SEM image of SG6_3[15].

\section{RESULTS AND DISCUSSION}

\section{Morphology of Fracture Surfaces}

The typical SEM images of fracture surfaces containing SG6_3 (5 wt.\% loading, which is approximately $1.65 \mathrm{wt} . \% \mathrm{CNT}$ ) show that the CNTs still remain on the silica surface 
even after being subjected to strong shear force during composite processing (Figure 2). The dispersion of CNTs appeared to be restricted by the silica, where the CNTs were dispersed along the silica circumference.In contrast, non-grafted CNTs agglomerate and disperse randomly within the epoxy [18].
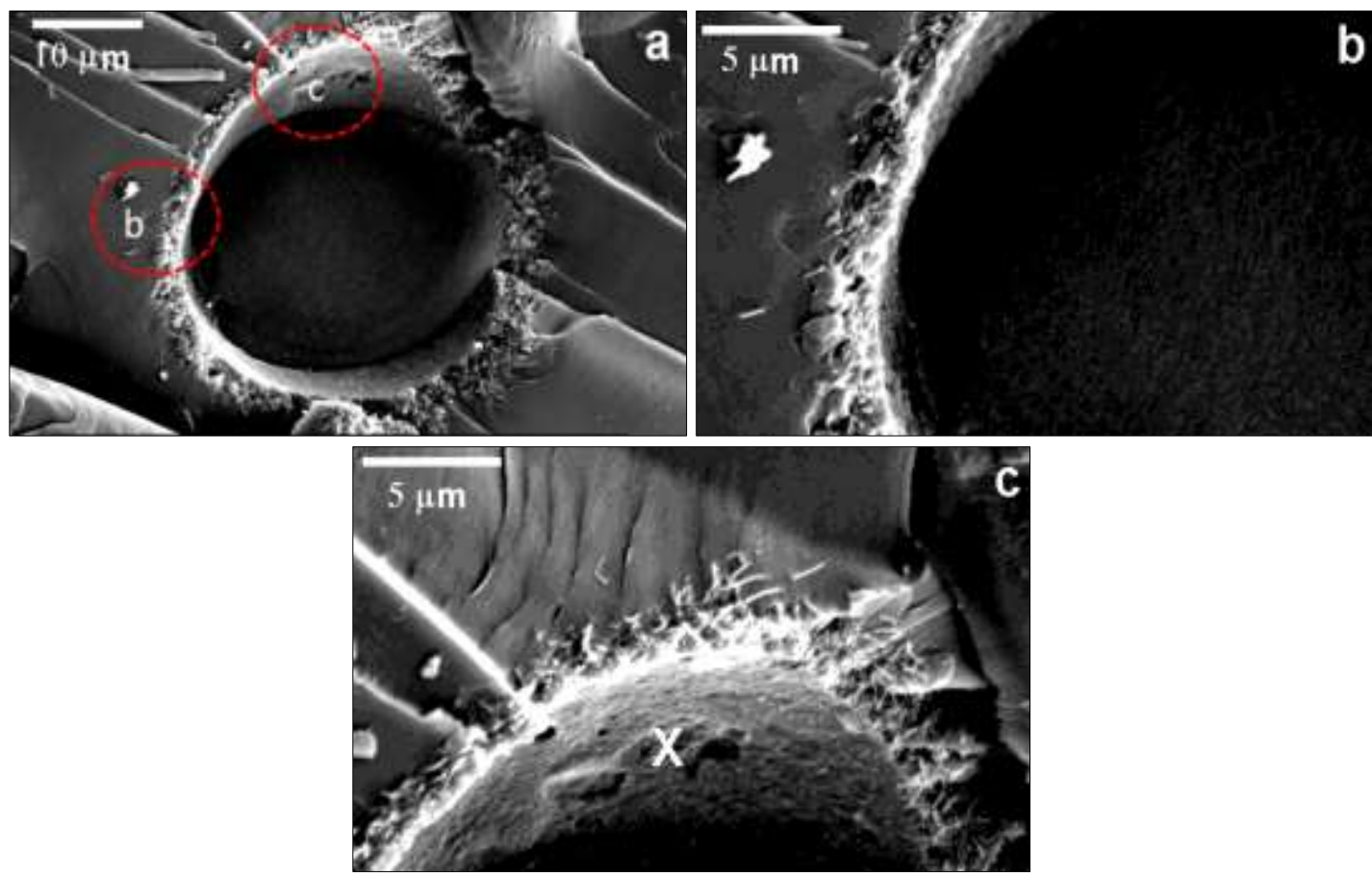

Figure 2. Typical SEM images of fractured surface of $5 \mathrm{wt} . \%$ SG6_3 ( $p_{\mathrm{CNT}}=1.65$ wt.\%) based epoxy composites. (b) and (c) show an enlarged image of the area marked by rings in (a).

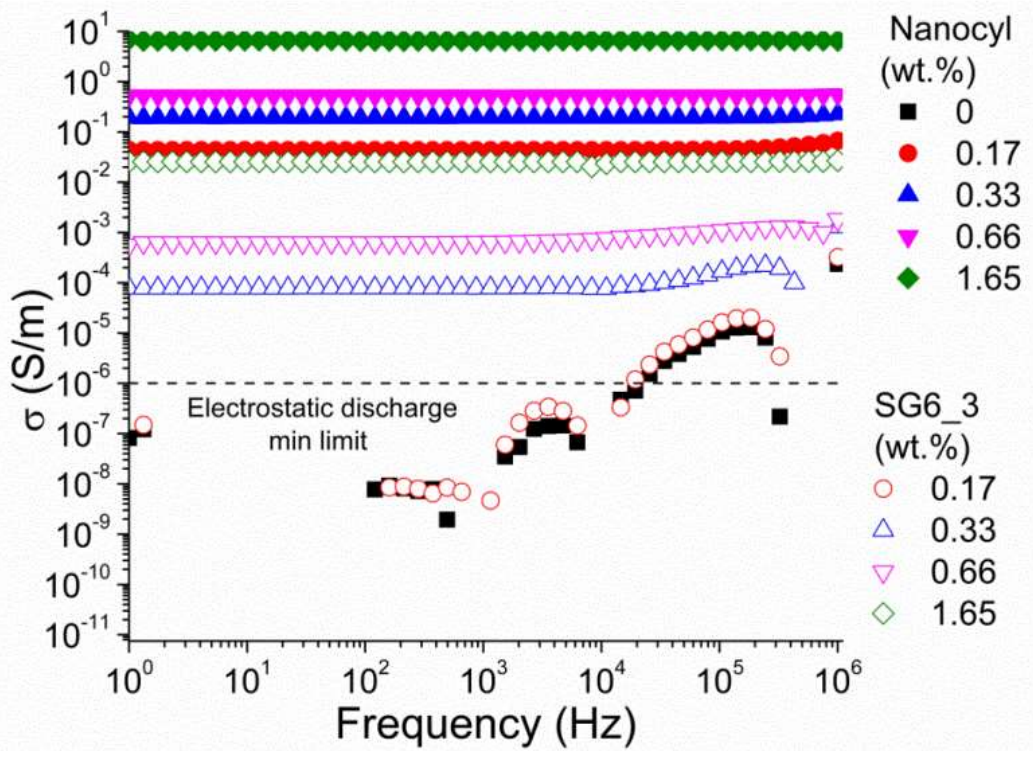

Figure 3. Specific conductivity as a function of frequency for SG6_3 and Nanocyl epoxy based composites. The dotted line represents the minimum conductivity requirement needed for fabricating materials that dissipate electrostatic charge[19]. 


\section{Impedance Spectroscopy}

Figure 3 shows the specific conductivity, $\sigma$, of both the Nanocyl and SG6_3 epoxy composites as a function of CNT loading. Due to equipment limitations, the impedance data for the neat epoxy at low frequency, from $1 \mathrm{~Hz}$ to $91 \mathrm{~Hz}$, were negative, which may be interpreted as noise. As such, they are omitted and not plotted in this graph. The conductivity data are published by[18].In spite of their 3-D isotropic structure, the ability of SG6_3 to form a conductive network at the same CNT loading is not as good as Nanocyl. Nevertheless, the addition of just 0.33 wt.\% SG6_3 is found to be sufficient for the fabrication of a composite that dissipates electrostatic charge on its surface.

\section{Circuit Model Representation}

The plots of real impedance (Z') versus imaginary impedance (Z') for nanocomposites containing SG6_3 are shown in Figure $4(\mathrm{a}-\mathrm{c})$. The composites containing SG6_3 for all loadings exhibit a semi-circular shape. The RC parallel model that consists of two components is proposed to describe the impedance behaviour of the sample (Figure 4d) $[20,21]$.This model takes into consideration the impedance response coming from the CNT (cluster) and epoxy matrices (interface).The related equations to describe twocomponent RC parallel models are as follows:

$$
\begin{gathered}
Z^{*}(\omega)=Z^{\prime}(\omega)-j Z^{\prime \prime}(\omega) \\
Z^{\prime}(\omega)=\frac{R_{1}}{1+\left(\omega C_{1} R_{1}\right)^{2}}+\frac{R_{2}}{1+\left(\omega C_{2} R_{2}\right)^{2}} \\
Z^{\prime \prime}(\omega)=\frac{\omega C_{1} R_{1}^{2}}{1+\left(\omega C_{1} R_{1}\right)^{2}}+\frac{\omega C_{2} R_{2}^{2}}{1+\left(\omega C_{2} R_{2}\right)^{2}}
\end{gathered}
$$

where $\mathrm{R}_{1}$ is the resistor from the cluster (particle)

$\mathrm{C}_{1}$ is the capacitor from the cluster (particle).

$\mathrm{R}_{2}$ is the resistor from the interface (epoxy).

$\mathrm{C}_{2}$ is the capacitor interface (epoxy).

\begin{tabular}{|c|c|c|c|c|c|c|}
\hline \multirow{3}{*}{$p_{\mathrm{CNT}}(\mathrm{wt} . \%)$} & \multicolumn{2}{|c|}{ Clusters } & \multicolumn{2}{|c|}{ Interface } & \multirow{2}{*}{\multicolumn{2}{|c|}{$\begin{array}{c}\text { Coefficient of } \\
\text { determination, } \mathrm{R}^{2}\end{array}$}} \\
\hline & \multirow{2}{*}{$\mathrm{R}_{1}(\Omega)$} & \multirow{2}{*}{$\mathrm{C}_{1}(\mathrm{~F})$} & \multirow{2}{*}{$\mathrm{R}_{2}(\Omega)$} & \multirow{2}{*}{$\mathrm{C}_{2}(\mathrm{~F})$} & & \\
\hline & & & & & $Z^{\prime}$ & Z', \\
\hline 1.65 & 40 & $2.9 \times 10^{-7}$ & $1.1 \times 104$ & $5 \times 10^{-11}$ & 0.999 & 0.999 \\
\hline 0.66 & $1.4 \times 10^{3}$ & $9 \times 10^{-10}$ & $2.6 \times 105$ & $5.4 \times 10^{-11}$ & 0.987 & 0.998 \\
\hline 0.33 & $7.1 \times 10^{4}$ & $1 \times 10^{-8}$ & $3.6 \times 106$ & $5 \times 10^{6}$ & 0.905 & 0.914 \\
\hline
\end{tabular}

Table 1. Parameters determined by fitting results for SG6_3-epoxy to the circuit model shown in Figure 4d.

Accordingly, the values of the parameters obtained by fitting are shown in Table 1. Since the $\mathrm{R}^{2}$ values $>0.9$ for both $Z$ ' and $Z$ ', the model proposed describes the data accurately. The values of $R_{1}$ are less than the values of $R_{2}$ for all loadings, which is expected, as the $R_{1}$ is the resistive element from the cluster components. The difference between $\mathrm{R}_{1}$ and $\mathrm{R}_{2}$ becomes more apparent at higher loadings, which demonstrates the effectiveness of SG6_3 in forming a conductive network within the epoxy matrix. 


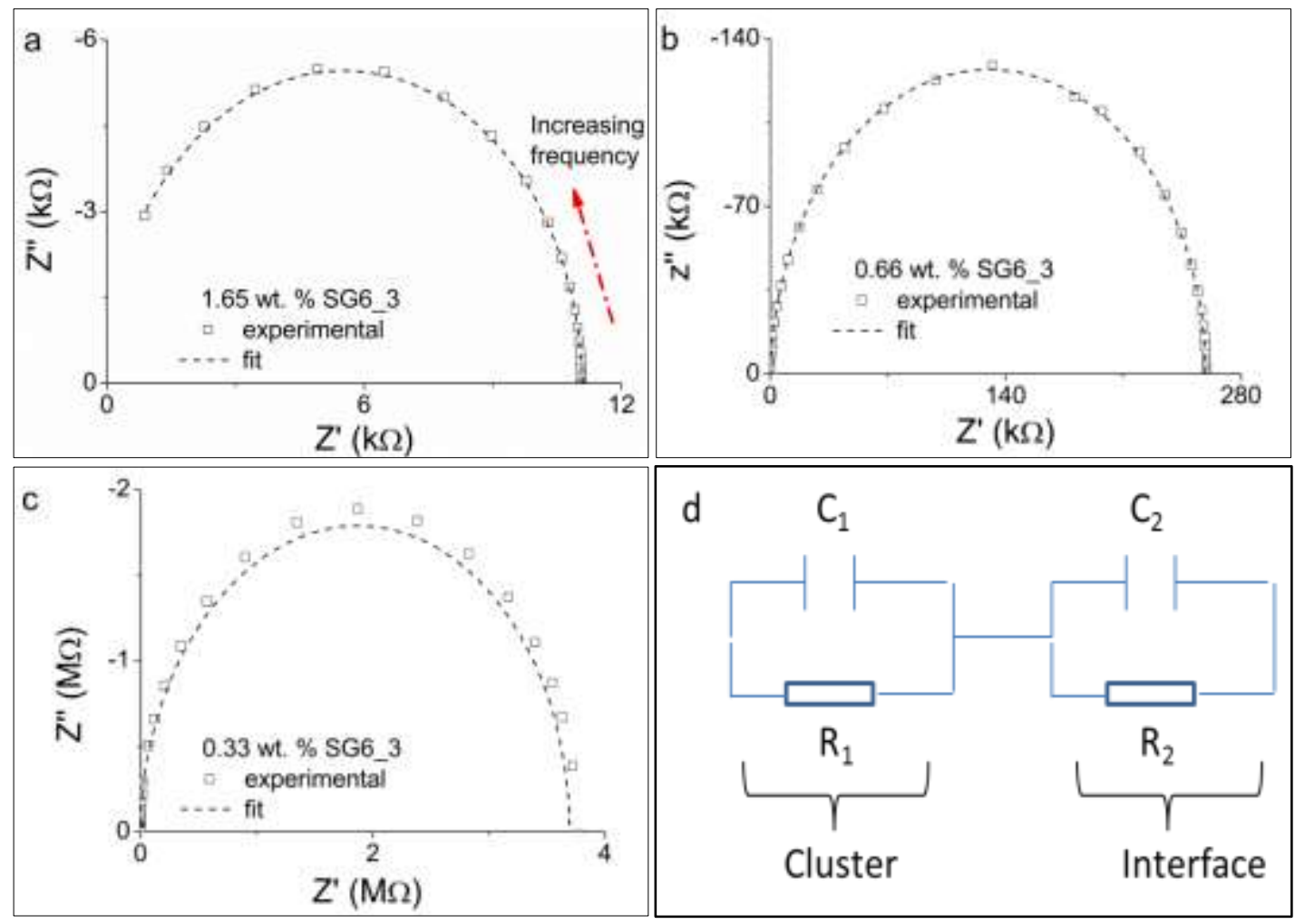

Figure 4. The complex impedance plane plots for SG6_3-epoxy samples with the following loadings of: $1.65 \mathrm{wt} . \%$ (a), $0.66 \mathrm{wt} . \%$ (b), and $1.65 \mathrm{wt} . \%$ (c). The square symbols are the experimental data while the dashed line is the fitted model. The direction of the increasing frequency is as shown in (a). Circuit equivalent model to represent the electrical properties of these composites (d).

\section{Insulator-Conductor Transition Analysis}

The addition of SG6_3 enhances the electrical properties of an epoxy resin. By continuously adding fillers, the composite's conductivity increases a few orders of magnitude (Figure 3). The critical percolation threshold, $p_{c}$ indicates the critical loading that causes this significant increase in the conductivity. After this point, the addition of more filler only causes a moderate increase in conductivity. Figure 5 compares the plot of specific conductivity obtained at $100 \mathrm{~Hz}$ as a function of filler loadings. Fitting yielded a $p_{\mathrm{c}}$ of 0.03 wt. $\%$ with $\mathrm{R}^{2}=0.9816$ for Nanocyl-epoxy, whereas a $p_{\mathrm{c}}$ of 0.16 wt.\% with $\mathrm{R}^{2}=0.9946$ is obtained for SG6_3-epoxy. Given the same matrices and processing conditions, the percolation threshold of the SG6_3 is an order of magnitude higher than Nanocyl.

The orientation of the conductive fillers within a matrix greatly affects the formation of a percolated network. CNTs were grown within SG6 pores as well as on the substrate's spherical surface. As such, CNTs are uniformly distributed radially along the substrate's surface. This geometry has the advantage that any properties imparted by SG6_3 to the matrices are isotropic in nature. This particle arrangement is preferred if an improvement in the mechanical properties of a composite by adding conductive reinforcement is required. On the other hand, non-grafted CNTs may freely rotate within a matrix depending on the shear force applied during processing. However, Du et al. [22] have shown that, by comparing the alignment of single-walled CNTs (SWNTs) 
in SWNT/PMMA composites, the highest conductivity is achieved for slightly aligned SWNTs compared to isotropic SWNTs. The orientation was determined from full-width half-maximum (FWHM) data from X-ray diffraction (XRD). In a separate study, Behnam et al. [23] performed Monte Carlo simulations to calculate the electrical resistivity resulting from CNT alignment and reached the same conclusion as Du et al. [22]. Moreover, agglomerates of CNT with random CNT distribution have been shown to be crucial to achieve a conductive network in epoxy resins [24-28] and also polymer melts [26, 29-31]. By manipulating the shear force during processing, CNTs may form agglomerates which allow percolation to take place at loading as low as $0.0025 \mathrm{wt} \%$ [24]. In the case of SG6_3, strong interaction between the silica and CNT yields a stable structure which will restrict CNTs' movement to form clusters. Based on this argument, the isotropic structure of SG6_3 results in the order of magnitude higher percolation threshold achieved in the cured epoxy in this work compared to the non-grafted Nanocyl.

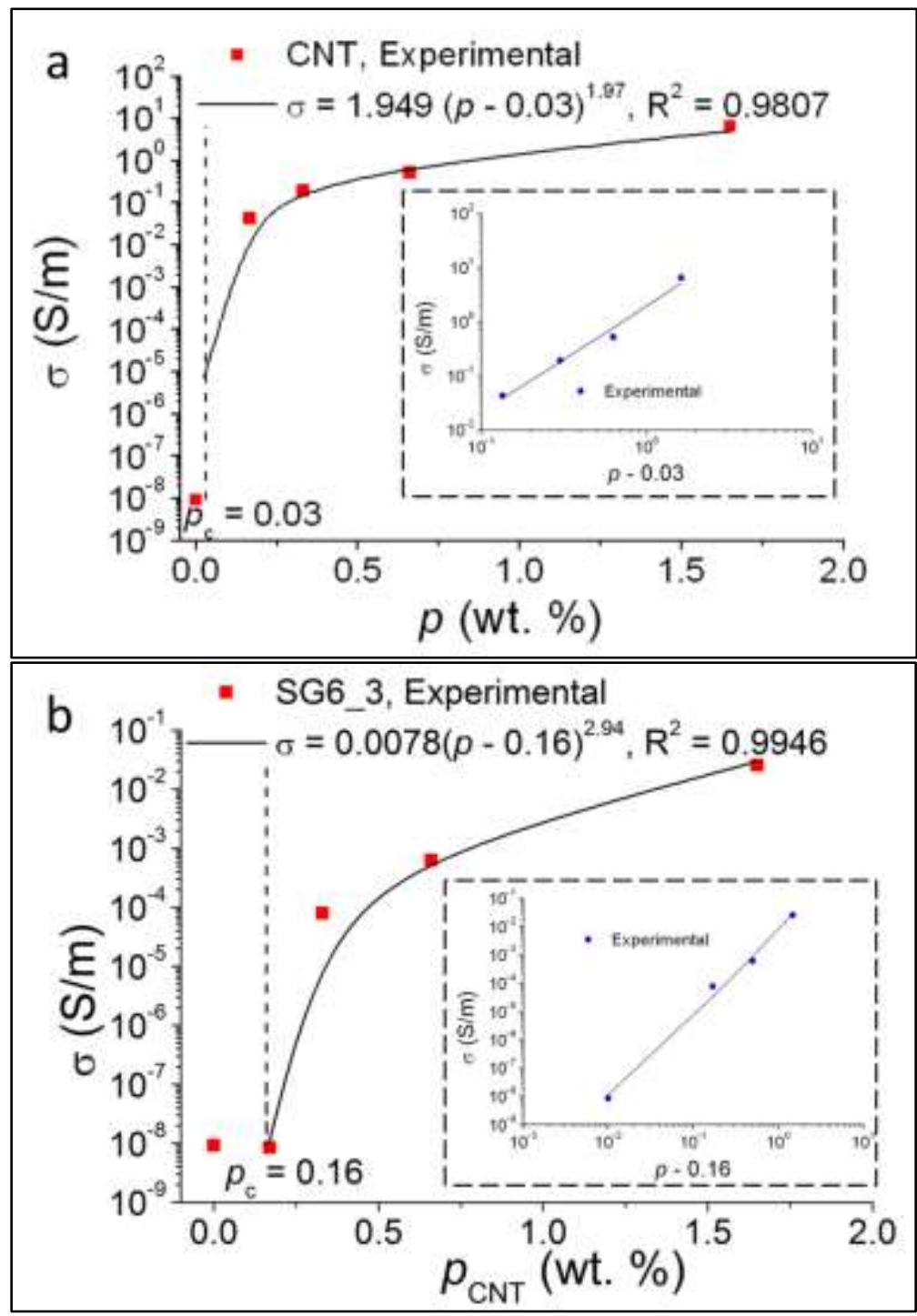

Figure 5. Semi-log plot of specific conductivity obtained from Nanocyl-epoxy (a) and SG6_3-epoxy (b) as a function of $p$. The inset showing a fit to the equation is derived from percolation theory [32]. 
Another possible reason for the difference in $p_{\mathrm{c}}$ is because Nanocyl and SG6_3 possess different aspect ratio values. The aspect ratio of a particle is defined as the ratio of its length to its diameter. SG6_3 consists of CNTs grown radially on its surface. Macroscopically, the aspect ratio of SG6_3 may be approximated to a sphere, which is 1 . On the other hand, based on the manufacturer's data, the aspect ratio of the CNTs used in this work is approximately 158 [33]. It is known that the geometry of the particles, or more accurately the aspect ratio, greatly influences the value of $p_{\mathrm{c}}$. A higher aspect ratio results in the percolated network forming at lower loading and vice versa $[24,34]$. For example, Hernandez et al. [35] measured the $p_{\mathrm{c}}$ of PVOH-based nanocomposites upon incorporating carbon nanodiscs (CND) of lower aspect ratio and CNT of higher aspect ratio, to be 2.1 and 0.4 vol.\%, respectively, which is an order of magnitude different. Similarly, Sandler et al. [24] also showed that the value of $p_{\mathrm{c}}$ obtained from spherical carbon black is at least two orders of magnitude higher than CNT.

\section{CONCLUSIONS}

The electrical conductivity of the cured composite was calculated to assess the ability of SG6_3 to form a percolated network. A two-component parallel RC circuit model was proposed to represent the impedance interactions within the sample and was found to fit the data well. Percolation theory was used to determine the critical loading $p_{\mathrm{c}}$, the values for which are $0.03 \mathrm{wt} . \%$ and $0.16 \mathrm{wt} . \%$ for the Nanocyl and SG6_3 respectively. This difference was explained in terms of filler alignment and aspect ratio; anisotropic alignment and a high aspect ratio favour the formation of an electrically percolated network at lower loadings, as opposed to isotropic and low aspect ratio particles.

\section{AKNOWLEDGEMENTS}

We would like to thank Ministry of Higher Education, Malaysia for funding and Prof Ian Kinloch for useful discussion.

\section{REFERENCES}

[1] Coleman JN, Khan U, Blau WJ, Gun'ko YK. Small but strong: A review of the mechanical properties of carbon nanotube-polymer composites. Carbon. 2006;44:1624-52.

[2] Bachtiar D, Sapuan SM, Hamdan MM. Flexural properties of alkaline treated sugar palm fibre reinforced epoxy composites. International Journal of Automotive and Mechanical Engineering. 2010;1:79-90.

[3] Jeffrey KJT, Tarlochan F, Rahman MM. Residual strength of chop strand mats glass fiber/epoxy composite structures: Effect of temperature and water absorption. International Journal of Automotive and Mechanical Engineering. 2011;4:504-19.

[4] Ravi Sankar H, Srikant RR, Vamsi Krishna P, Bhujanga Rao V, Bangaru Babu P. Estimation of the dynamic properties of epoxy glass fabric composites with natural rubber particle inclusions. International Journal of Automotive and Mechanical Engineering. 2013;7:968-80. 
[5] Bauhofer W, Kovacs JZ. A review and analysis of electrical percolation in carbon nanotube polymer composites. Composites Science and Technology. 2009;69:1486-98.

[6] Xie XL, Mai YW, Zhou XP. Dispersion and alignment of carbon nanotubes in polymer matrix: A review. Materials Science \& Engineering R-Reports. 2005;49:89-112.

[7] Qian H, Bismarck A, Greenhalgh ES, Kalinka G, Shaffer MSP. Hierarchical composites reinforced with carbon nanotube grafted fibers: The potential assessed at the single fiber level. Chem Mat. 2008;20:1862-9.

[8] Qian H, Bismarck A, Greenhalgh ES, Shaffer MSP. Synthesis and characterisation of carbon nanotubes grown on silica fibres by injection CVD. Carbon. 2010;48:277-86.

[9] Yamamoto N, Hart AJ, Garcia EJ, Wicks SS, Duong HM, Slocum AH, et al. High-yield growth and morphology control of aligned carbon nanotubes on ceramic fibers for multifunctional enhancement of structural composites. Carbon. 2009; 47:551-60.

[10] Huang SM. Growing carbon nanotubes on patterned submicron-size SiO2 spheres. Carbon. 2003;41:2347-52.

[11] Agrawal S, Kumar A, Frederick MJ, Ramanath G. Hybrid microstructures from aligned carbon nanotubes and silica particles. Small. 2005;1:823-6.

[12] He DL, Bozlar M, Genestoux M, Bai JB. Diameter- and length-dependent selforganizations of multi-walled carbon nanotubes on spherical alumina microparticles. Carbon. 2010;48:1159-70.

[13] Xiang R, Luo G, Qian W, Wang Y, Wei F, Li Q. Large area growth of aligned CNT Arrays on spheres: towards large scale and continuous production. Chemical Vapor Deposition. 2007;13:533-6.

[14] Nguyen XH, Lee YB, Lee CH, Lim DS. Synthesis of sea urchin-like particles of carbon nanotubes directly grown on stainless steel cores and their effect on the mechanical properties of polymer composites. Carbon. 2010;48:2910-6.

[15] Othman RN, Kinloch IA, Wilkinson AN. Synthesis and characterisation of silica-carbon nanotube hybrid microparticles and their effect on the electrical properties of poly(vinyl alcohol) composites. Carbon. 2013;60:461-70.

[16] Adebisi AA, Maleque MA, Rahman MM. Metal matrix composite brake rotor: Historical development and product life cycle analysis. International Journal of Automotive and Mechanical Engineering. 2011;4:471-80.

[17] Salleh Z, Yusop MYM, Rosdi MS. Mechanical properties of activated carbon (AC) coir fibers reinforced with epoxy resin. Journal of Mechanical Engineering and Sciences. 2013;5:631-8.

[18] Sandler J, Shaffer MSP, Prasse T, Bauhofer W, Schulte K, Windle AH. Development of a dispersion process for carbon nanotubes in an epoxy matrix and the resulting electrical properties. Polymer. 1999;40:5967-71.

[19] Kenneth B. K. Teo CS, Manish Chhowalla, William I. Milne. Catalytic Synthesis of Carbon Nanotubes and Nanofibers. In: Nalwa HS, editor. Encyclopedia of Nanoscience and Nanotechnology: American Scientific Publisher; 2003. p. 1-22.

[20] Gerhardt RA. Impedance Spectroscopy and Mobility Spectra. Encyclopedia of Condensed Matter Physics. London: Elsevier; 2005. p. 350-63. 
[21] Garrett MP, Ivanov IN, Gerhardt RA, Puretzky AA, Geohegan DB. Separation of junction and bundle resistance in single wall carbon nanotube percolation networks by impedance spectroscopy. Appl Phys Lett. 2010;97.

[22] Du FM, Fischer JE, Winey KI. Effect of nanotube alignment on percolation conductivity in carbon nanotube/polymer composites. Phys Rev B. 2005;72.

[23] Behnam A, Guo J, Ural A. Effects of nanotube alignment and measurement direction on percolation resistivity in single-walled carbon nanotube films. J Appl Phys. 2007;102.

[24] Sandler JKW, Kirk JE, Kinloch IA, Shaffer MSP, Windle AH. Ultra-low electrical percolation threshold in carbon-nanotube-epoxy composites. Polymer. 2003;44:5893-9.

[25] Martin CA, Sandler JKW, Windle AH, Schwarz MK, Bauhofer W, Schulte K, et al. Electric field-induced aligned multi-wall carbon nanotube networks in epoxy composites. Polymer. 2005;46:877-86.

[26] Bauhofer W, Schulz SC, Eken AE, Skipa T, Lellinger D, Alig I, et al. Shearcontrolled electrical conductivity of carbon nanotubes networks suspended in low and high molecular weight liquids. Polymer. 2010;51:5024-7.

[27] Abdul Majid MS, Daud R, Afendi M, Amin NAM, Cheng EM, Gibson AG, et al. Stress-strain response modelling of glass fibre reinforced epoxy composite pipes under multiaxial loadings. Journal of Mechanical Engineering and Sciences. 2014;6:916-28.

[28] Afendi M, Athirah N, Abdul Majid MS, Daud R, Teramoto T. Experimental and numerical investigation of V-shaped epoxy adhesive joints. Journal of Mechanical Engineering and Sciences. 2014;6:929-39.

[29] Skipa T, Lellinger D, Saphiannikova M, Alig I. Shear-stimulated formation of multi-wall carbon nanotube networks in polymer melts. Phys Status Solidi BBasic Solid State Phys. 2009;246:2453-6.

[30] Hardinnawirda K, SitiRabiatull Aisha I. Effect of rice husks as filler in polymer matrix composites. Journal of Mechanical Engineering and Sciences. 2012;2:181-6.

[31] M. Khairul Zaimy AG, Zafiah A, Rus M, Ab Latif N, Nurulsaidatulsyida S. Mechanical and thermal properties of waste bio-polymer compound by hot compression molding technique. Journal of Mechanical Engineering and Sciences. 2013;5:582-91.

[32] Stauffer D, Aharony A. Introduction to percolation theory. London: Taylor and Francis; 1994.

[33] Nanocyl. Nanocyl ${ }^{\mathrm{TM}}$ NC 7000 Thin Multiwall Carbon Nanotubes. Sambreville, Belgium2009.

[34] McKee GSB, Deck CP, Vecchio KS. Dimensional control of multi-walled carbon nanotubes in floating-catalyst CVD synthesis. Carbon. 2009;47:2085-94.

[35] Hernandez YR, Gryson A, Blighe FM, Cadek M, Nicolosi V, Blau WJ, et al. Comparison of carbon nanotubes and nanodisks as percolative fillers in electrically conductive composites. Scr Mater. 2008;58:69-72. 